\title{
Promoting healthy eating and active playtime by connecting to nature families with preschool children: evaluation of pilot study "Play\&Grow"
}

\author{
Tanja Sobko' ', Zhenzhen Jia', Matthew Kaplan², Alfred Lee' and Chia-huei Tseng ${ }^{3}$
}

BACKGROUND: This pilot project aimed to evaluate the "Play\&Grow" program which promotes age-appropriate dietary habits and playtime healthy routines through "connectedness to nature" experiences in Hong Kong families with young children.

METHOD: Thirty-eight preschoolers (aged 33.97 $\pm 9.38 \mathrm{mo}$ ), mothers, and their domestic workers were recruited. The families attended one workshop/week for a 4-mo period, consisting of: (i) health topic; (ii) food games; (iii) nature-related outdoor activities.

RESULTS: Feeding practices, particularly Promoting and Encouragement to eat (PE) and Instrumental Feeding (IF) improved after the intervention ( $P=0.008$ and $P=0.016$, respectively). Mother's BMI, responsibility for child's meal, child's birth weight had a bearing on the improvement of $P E, r^{2}=0.243$, $F(3,33)=3.54, P=0.025$. Domestic helper's responsibility for child's cooking and her IF practices could predict child's picky eating $\left(r^{2}=0.203, F(2,34)=4.322, P=0.021\right)$. Mother's responsibility for child and helper's responsibility for cooking could predict child's consumption of salty foods $\left(r^{2}=0.252, F(2,34)=\right.$ $5.737, P=0.007)$. Physical activity of caregivers improved after the intervention.

CONCLUSION: The pilot confirmed the design, protocols, evaluation instruments, and logistics of the study. Modified "Play\&Grow" intervention will be conducted in a more rigorous randomized controlled trial to determine the long-term impact on obesity prevention in Hong Kong.

G ood nutrition and active life style are two building blocks for a healthy life (1). Children in big cities including Hong Kong (HK) have less exposure to nature $(2,3)$, engage in sedentary activities, have poor eating habits, and get insufficient sleep compared with the previous generations $(4,5)$, hence children's health is becoming a prominent public concern, resulting in a rise in obesity prevalence (6); $4.7 \%$ of the HK $2 \mathrm{y}$ olds are overweight/obese (4-6). At the same time, HK parents employ inappropriate strategies in managing the physical activities and dietary habits of their children, such as forced feeding, watching TV while eating, etc (4-6). Our intervention therefore targeted parents of young children as well as foreign domestic workers (domestic helpers), as they not only perform household chores but are highly involved in taking daily care of the children in HK $(7,8)$, influencing their habits and routines (9). Nature-related activities enhance general well-being, as reflected in increased physical activity, a healthier diet, reduced stress, and better sleep (10-13). Most of the available intervention programs focus almost exclusively on diet and physical activity (14), and although some health promoting programs (15-17) worldwide have started to include gardening and connections to farms, none in HK to the best of our knowledge has taken into consideration a family's interactions with nature. Health habits are developed very early in life, making it critical to start lifestyle interventions as early as possible (18). Hence, it is timely and highly relevant to develop new multi-dimensional lifestyle intervention programs and test their effectiveness for preschool children.

The main aim of the pilot study was to develop and test the study protocols, session scripts, logistics, measuring instruments, and program adherence. The secondary aim was to test the hypothesis that the intervention activities may induce positive changes in caregivers' feeding habits, their physical activity levels, and eating and activity habits in preschool children.

\section{METHODS}

Conceptual Influences and Theoretical Framework

Similar to INFANT (19), one of the most effective lifestyle parenting programs, the Play\&Grow intervention used anticipatory guidance framework (20,21) in addressing the caregivers' feeding, eating, and sedentary habits of children aged 2 to 4 (22). The detailed protocol of "Play\&Grow" is described elsewhere (23).

\section{Participants}

Children from 2 to $4 \mathrm{y}$ of age and their caregivers in HK were recruited and allocated to one of the two study sites, according to their residential addresses. Both parents were encouraged to participate, but largely only the domestic helpers (all females) and sometimes the mothers attended the sessions. The same caregivers were required to complete the questionnaires and to attend at least $80 \%$ of the program. After

\footnotetext{
Trial registration ClinicalTrail. gov: ISRCTN73824458

${ }^{1}$ School of Biological Sciences, Faculty of Science, The University of Hong Kong, Hong Kong; ${ }^{2}$ Department of Agricultural Economics, Sociology and Education, Pennsylvania State University, State College, Pennsylvania; ${ }^{3}$ Research Institute of Electrical Communication, Tohoku University, Sendai, Japan. Correspondence: Tanja Sobko (tsobko@hku.hk)

Received 15 June 2016; accepted 4 October 2016; advance online publication 25 January 2017. doi:10.1038/pr.2016.251
} 
three families dropped out, 39 preschoolers (21 boys and 18 girls), 38 mothers and 38 domestic helpers (all females) chose to participate in the program (one family had two children). Three families, who decided to withdraw from the program, due to the lack of time did not differ in demographic characteristics from the rest of the families. The study was approved by the University of Hong Kong Human Research Ethics Committee for ethical clearance for research involving human participants (nr: EA1502073). It was carried out in accordance with The Code of Ethics of the World Medical Association (Declaration of Helsinki) for experiments involving humans.

The demographic data of the caregivers and children were collected via questionnaires. The anthropometric data (height, weight) was aggregated according to the international age-adjusted references $(24,25)$ and converted to BMI $\left(\mathrm{kg} / \mathrm{m}^{2}\right)$ for each adult participant, and standardized for age and gender for children using BMI-for-age $z$-scores $(26,27)$. The sample quality control performed during data entry, a second research assistant re-entered the data with randomly chosen sample questionnaires and found over $90 \%$ of consistency between these coders. All of the demographic and anthropometry data are presented in Table 1. No significant difference in any anthropometry data was detected between the groups of the two sites (New Territories and Hong Kong Island). Mean age of the preschoolers was 33.97 mo, with a mean $z$-BMI of -9.38 . The domestic helpers $(n=28$, $73.7 \%$ ) were responsible for cooking meals for children, and took the main responsibility of looking after children $(n=20,52.6 \%)$.

\section{Intervention}

Table 2 provides a brief description of each of 12 discussion sessions and parenting practices. Educational strategies included direct instruction, caregiver peer supports, group discussions and homework tasks. All the elements were developed prior to the start of the intervention. Each session, led by a group leader and a co-leader comprised of: (i) $15 \mathrm{~min}$ of guided active play involving both children and caregivers; (ii) $15 \mathrm{~min}$ of interactive education and skill development for caregivers; simultaneously supervised active play with foods for children, to promote acceptance of vegetables, and (iii) $15 \mathrm{~min}$ of guided active nature games outdoors, involving both children and caregivers. Each session included a lifestyle component (regarding eating, physical activity/sedentary behaviors and "connectedness to nature") aimed at providing caregivers with knowledge and skills to support their child's healthy lifestyle. To compensate for limited "theory time", some additional "homework" was given to the families and feedback was provided during the next session. Examples of the additional novel "connectedness to nature" elements were: (i) $1 / 3$ of each session included active outdoor nature games, focusing on developing motor skills, discovering nature, and practicing awareness of sounds, touch, smells, and temperature; (ii) group activities, practicing nature tasks; (iii) nature homework with follow-ups (collecting nature subjects and making art, growing own plants); (iv) environmental care training (reducing paper waste, water saving, recycling); (v) studying new vegetables and cooking together with them (avocado, avocado boat, guacamole, etc.).

\section{Outcomes and Their Assessments}

Certain family-related factors were expected to be associated with the effectiveness of the intervention program. The caregivers after completing the program were expected to: (i) know more about healthy feeding, eating, active play and (ii) gain general and specific parenting practices, aiming to establish healthy habits. The children would: (i) eat healthier, be less fussy with food; (ii) be more active, less sedentary, and (iii) have a higher "connectedness to nature", reflected in increased time spent outside. The primary outcomes were categorized into feeding and eating habits; physical activity of caregivers and children's active play and "connectedness to nature" habits were deemed as secondary outcomes. Since no similar interventions in this age group in HK had taken place, we adopted the MEND assessment design (28). To test the effectiveness of this 4-mo pilot study, the tests on lifestyle habits were administered prior to and immediately after the intervention period. Figure 1 presents the general enrolment flow chart of this pilot study. Examples of some items used in the questionnaires are provided in Table 3.
Table 1. Participant characteristics at baseline measurement

\begin{tabular}{lcr}
\hline & $\begin{array}{c}\text { In total } \\
n(\%)\end{array}$ & Mean (SD) \\
\hline Children & $38(100)$ & \\
Gender (male) & $20(52.6)$ & \\
Age (month) & & $-.14(1.51)$ \\
z-BMl & & $3.23(4.62)$ \\
Weight of birth (kg) & & $49.37(3.22)$ \\
Length of birth (cm) & & \\
Mothers & & \\
Age (years) & $37(100)$ & $22.10(3.71)$ \\
BMl & & \\
$\begin{array}{l}\text { Delivery method (vaginal) } \\
\text { Work situation(employed) }\end{array}$ & $24(63.2)$ & \\
$\begin{array}{l}\text { Domestic helpers (all females) } \\
\text { Age (years) } \\
\text { BMl }\end{array}$ & $35(92.1)$ & $35(100)$ \\
$\begin{array}{l}\text { Education level (postsecondary } \\
\text { or above) }\end{array}$ & $11(28.9)$ & $23.09(3.60)$ \\
\hline
\end{tabular}

\section{Family-related factors}

Family structure (only parents and children)

Parental education level

(postsecondary or above)

Family income (HKD)

$12,001-40,000$

$40,001-60,000$

$>60,001$

Not the only child in the family

TVs at home $\geq 2$

None in child's room

Computer at home $\geq 2$

None in child's room

Responsible for looking after the child

Mothers

Helpers

Responsible for child's meal

Mothers

Helpers

Responsible for child's recipes

Mothers

Helpers

Responsible for the cooking method

Mothers

Helpers

Responsible for cooking

Missing $=1$

Mothers

$4(10.5)$

Helpers

$28(73.7)$

aOne family had two children participated in the study. 
Table 2. Intervention content

\begin{tabular}{ll}
\hline Session & Activities during the pilot study \\
\hline $\mathbf{1}$ & Welcome and Intro: Setting goals, Communication in the family. Introduce basic concepts regarding parental feeding styles and how \\
these might relate to beliefs about parenting and safety of children. CN/Outdoor play: active nature games, discovering nature, practicing \\
awareness to sounds, touch, smells, temperature, etc. \\
Healthy eating: Food groups, Reading food labels. How much to eat? Develop parents understanding regarding basic nutrition principals. \\
CN/Outdoor play: active nature games, discovering nature, practicing awareness to sounds, touch, smells, temperature, etc. \\
Active play: Methods to encourage active play. Decrease inactive time. Motor skill development for children-the foundation for an active \\
life and safety. Moving for healthy and sedentary behaviors in families. CN/Outdoor play: active nature games, discovering nature, practicing \\
awareness to sounds, touch, smells, temperature, etc.
\end{tabular}

Hong Kong weather: Methods to manage active play according to the changing weather in Hong Kong. Introduce how to play in hot or rainy weather and take safety precautions. CN/Outdoor play: active nature games, discovering nature, practicing awareness to sounds, touch, smells, temperature, etc.

Sleeping time: "Sleeping friend" and sleeping routines. Develop parents' understanding regarding sleeping behaviors. CN/Outdoor play: active nature games, discovering nature, practicing awareness to sounds, touch, smells, temperature, etc.

Fuzzy eating: The outside environment and children. Develop parental skills: how to feed/how to manage food rejections and demands. CN/Outdoor play: active nature games, discovering nature, practicing awareness to sounds, touch, smells, temperature, etc.

$7 \quad$ Limit setting: Power struggle. Portion size. Provide parents with understanding about feeding styles and its'impact on children's eating. CN/Outdoor play: active nature games, discovering nature, practicing awareness to sounds, touch, smells, temperature, etc.

$8 \quad$ Fun with food: Cooking together. To reinforce understanding about parental modelling of eating, sedentary and physical activities. CN/ Outdoor play: active nature games, discovering nature, practicing awareness to sounds, touch, smells, temperature, etc.

9

Special occasions: Healthy eating on special occasions, e.g., New Year, Birthday party, Easter, Mid-Autumn Festival and addressing concerns for when child is sick. CN/Outdoor play: active nature games, discovering nature, practicing awareness to sounds, touch, smells, temperature, etc.

10

Encouraging healthy habits: Rules and routines. Throwing, catching and bouncing. Develop skills of how to provide fail-safe food and activity environments. CN/Outdoor play: active nature games, discovering nature, practicing awareness to sounds, touch, smells, temperature, etc.

Nature and me: Run \& Fun: Promoting PA in Nature. Safe and fun in the nature. Develop parental skills of how to provide safe outdoor and nature activity environments. CN/Outdoor play: active nature games, discovering nature, practicing awareness to sounds, touch, smells, temperature, etc.

Farewell and graduation: Summary. CN/Outdoor play: active nature games, discovering nature, practicing awareness to sounds, touch, smells, temperature, etc.

\section{Dietary Habits, Physical Activity Habits, and Connectedness to Nature}

The Parental Feeding Style Questionnaire (PCFQ) (29) was used to assess parents' feeding practice by four subscales (instrumental feeding, emotional feeding, promoting and encouragement to eat, and control over eating) with 27 items. Children's eating behaviors were assessed using a 45 items HK Children's Dietary Habit Questionnaire (HKCDHQ, being currently validated) (30). The items of PCFQ and HKCDHQ were rated on a five-point Likert-scales, from 1 point (never) to 5 points (always). Physical activity duration was measured in minutes (including light-, moderate-, and vigorous intensity) and sedentary behavior was assessed via the International Physical Activity Questionnaire (31) for caregivers and Physical Activity Questionnaire for Preschool-aged Children (Pre-PAQ) $(32,33)$ for children. "Connectedness to nature" in children was measured using a nature relatedness scale, which is currently being validated by our research team. The intervention sessions ran once a week, and the intervention adherence was measured by the number of dropouts and qualitative group interviews at the beginning and the end of the study. Program orientation and debriefing meetings were held with program participants to provide some useful contextual information with regard to program participants' expectations and experience of "Play\&Grow" activities. As such, several discerning quotes are interspersed in the Discussion sections.

\section{Statistical Analysis}

All the data analyses were conducted using SPSS 20 (SPSS, Chicago, IL). Mean and SD were used to present continuous descriptive variables, frequency (percentage) for categorical variables. Due to the small sample size $(n=38)$, Wilcoxon signed-rank test or sign test was used to compare pre- and postintervention differences. The $r$ code indicated the effect size. Correlation analysis was performed between the family-related factors and the effectiveness of the intervention. Spearman's rank correlation was used for continuous variables, while Kruskal-Wallis test was used for categorical variables. Variables selected from correlation tests were included in a simultaneous multiple regression model. Results were considered as statistically significant when $P<0.05$, two-tailed.

\section{RESULTS}

Instrumental feeding (IF) and promoting and encouragement to eat (PE) behaviors of the caregivers improved significantly after the intervention. Among the 38 families, the caregivers' IF behaviors reduced significantly after the intervention $(z=$ $-2.416, P=0.016, r=0.391)$. In addition, after participating in the Play\&Grow program, caregivers performed positive parenting practices (i.e., promoting and encouragement to eat behaviors) more often $(z=-2.652, P=0.008, r=0.430)$. Furthermore, the data derived from the HK Children's Dietary Habit Questionnaire showed a significant improvement in the "battle during mealtime" (exact $P=0.007$ ), "picky eating" (exact $P=0.049$ ), "allowing consumption of salty food" (exact $P=0.039)$, and "supervision during the meals" $(\mathrm{z}=-2.285, P=$ $0.022, r=0.371$ ).

Domestic helper's vigorous $(z=-2.099, P=0.036, r=0.341)$, moderate $(z=-2.127, P=0.033, r=0.345)$ active time and mothers' vigorous active time during weekdays increased significantly 


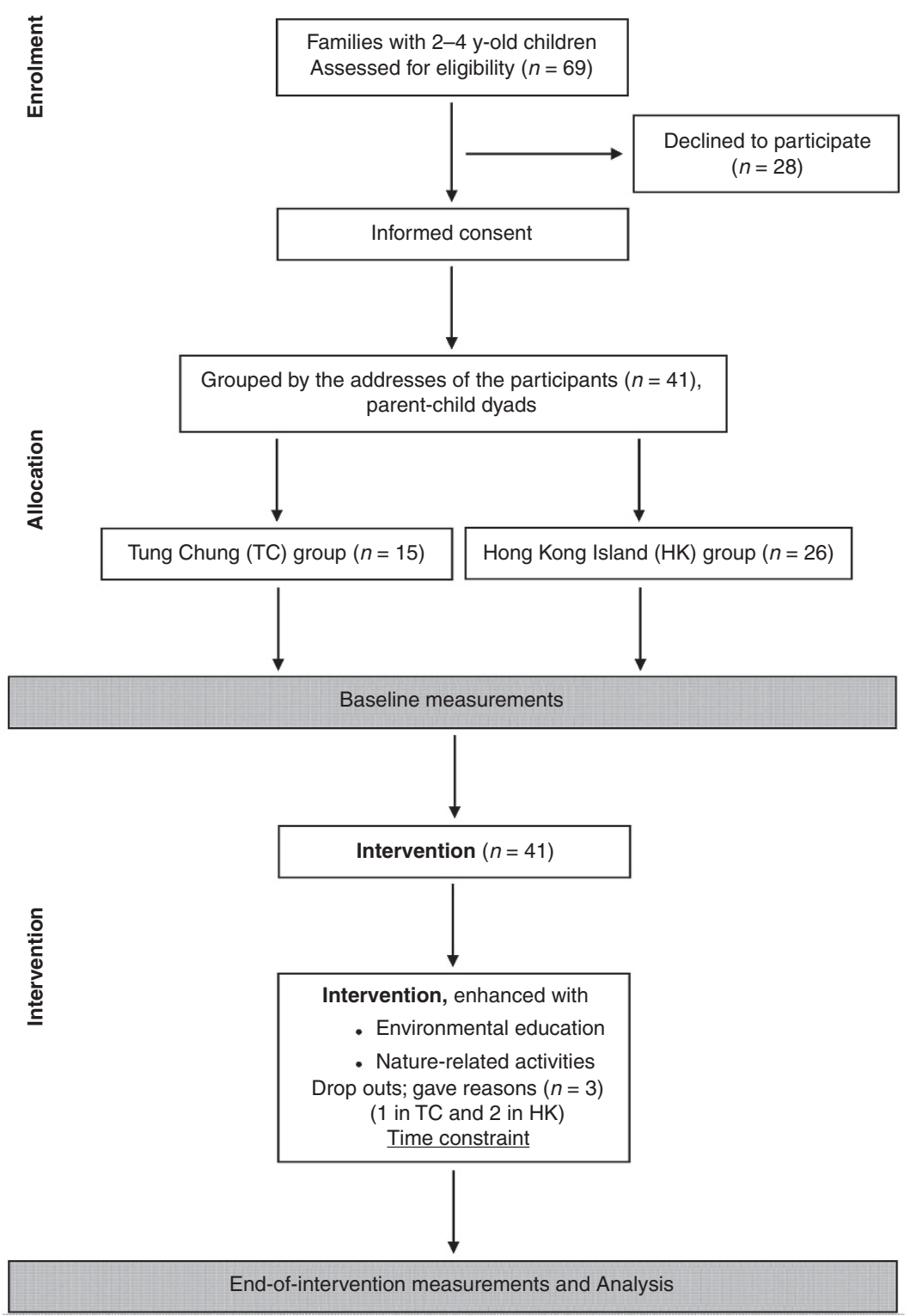

Figure 1. Enrolment flow chart.

during the intervention (exact $P=0.015)$. However, no differences were detected on child's playtime (as reported in the questionnaires). Table 4 presents all of the intervention outcomes.

\section{Factors That Influenced the Effectiveness of Intervention}

Families with a mother being responsible for child's meal $\left(x^{2}=44.952, P=0.026\right)$ and cooking $\left(x^{2}=4.656, P=0.031\right)$, child's birth weight $\left(r_{\mathrm{s}}=-0.433, P=0.007\right)$, and mother's BMI $\left(r_{\mathrm{s}}=0.362, P=0.028\right)$ were found to have a moderate bearing on the improvement of PE habits as one of a programs outcome. The domestic helper responsibility for child's cooking $\left(x^{2}=7.342, P=0.007\right)$, meals $\left(x^{2}=3.878, P=0.049\right)$, and her instrumental feeding practices $\left(r_{s}=0.393, P=0.015\right.$. $)$ correlated with improvement in child's picky eating behavior. The child's consumption of salty food correlated with mother's responsibility for the child $\left(x^{2}=4.215, P=0.040\right)$, and helper's responsibility for cooking $\left(x^{2}=4.075, P=0.044\right)$. Lastly, the supervision of the child during the meal correlated with the child's $z$-BMI $\left(r_{\mathrm{s}}=0.369, P=0.025\right)$, child's age $\left(r_{\mathrm{s}}=-0.392\right.$, $P=0.015)$, and mother's age $\left(r_{\mathrm{s}}=-0.327, P=0.048\right)$. Table 5 presents all the potential factors, which might influence participants' dietary habits. The influence on domestic helper's moderate active time correlated with the numbers of computers at home, $x^{2}=6.842, P=0.009$. Table 6 presents all the potential factors, which might influence participants' active time. None of the other family-related factors correlated with the effectiveness of intervention.

First, only three of the previously mentioned potential factors (i.e., mother's BMI, child's birth weight, the responsibility for child's meal) together significantly contributed to predicting the influence on PE behavior in the simultaneous regression model. These three factors could together predict the outcome of this program on caregiver's PE behavior, $F(3,33)$ $=3.540, P=0.025, r^{2}=0.243$ and could explain $24.3 \%$ of the 
Articles | Sobkoetal.

Table 3. Examples of some items used in the questionnaires for Play\&Grow

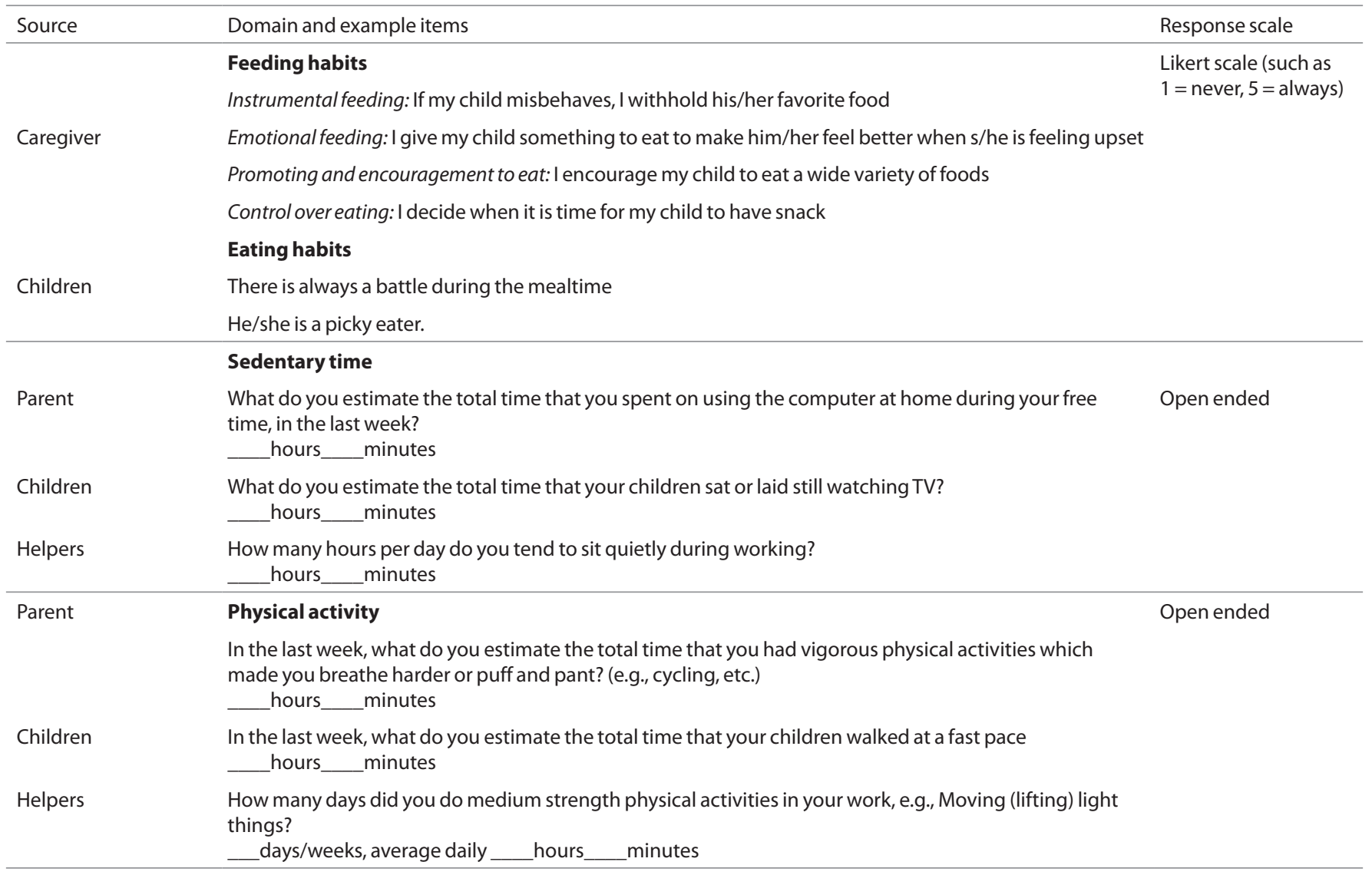

variability of the effectiveness of intervention on caregiver's PE behavior. Second, only two previously mentioned potential factors (i.e., IF and responsibility for cooking) together could significantly contribute to a regression model and predict the effectiveness of this program on the "picky eater" behavior, $F$ $(2,34)=4.322, P=0.021, r^{2}=0.203$, explaining $20.3 \%$ of the variability of the effectiveness. Lastly, the two factors (supervision of the child during the meals and responsibility for cooking the child's meal) could predict the outcome of "allowing the child to consume salty food", $F(2,34)=5.737, P=0.007$, $r^{2}=0.252$; this could explain $25.2 \%$ of the variability of the effectiveness of intervention regarding this behavior. All of the regression results can be found in Table 7 .

\section{DISCUSSION}

A recent Cochrane review reported only a marginally significant improvement on body weight after some interventions and little to no effect on dietary or physical activity behaviors (34). It is worth noting that, in contrast to the study reported in the Cochrane review, our intervention program, even in the pilot form, indeed found highest impact on the caregivers feeding habits: the instrumental feeding (IF) and promoting and encouragement to eat (PE) behaviors of the caregivers improved significantly after the intervention. This finding is of relevance as parental dietary behavior is a significant predictor for child's dietary habits (35). Several family-based intervention programs have demonstrated efficient outcomes on preschoolers $(19,36)$ and prepubescent children (37) lifestyles. There is indication that the acquisition of healthy dietary habits (such as adequate vegetable/fruit consumption and dairy-rich intake) of young children participating in health promotion interventions can contribute to sustainable benefits after 2 y (34).

As suggested above, the parents have profound influence on children's food habits and preferences (35). Our findings underline the importance of acknowledging and providing training for all caregivers in the family setting, including domestic helpers who influence children's eating habits and physical activity patterns. We found that when the domestic helper was responsible for child's cooking, her instrumental feeding practices predicted improvements in child's picky eating behavior. Despite the mother being a primary caregiver, if the helper took responsibility for the cooking, this would lead to healthier eating habits of children, as for example, decrease in the consumption of salty foods after the intervention. It is quite possible that domestic helpers play a more important role in influencing the development of food acceptance patterns of young children than previously anticipated as the domestic helpers spend much time with children and become their natural role models (7) in HK (8). The intent of the program was to include the domestic helpers as well as the parents and intensively engage both in the program. Comments made by several parents and caregivers during the post-program debriefing 
Table 4. Comparison between pre- and post-test

\begin{tabular}{|c|c|c|c|}
\hline Outcomes & $\begin{array}{l}\text { Pretest } \\
\text { median }\end{array}$ & $\begin{array}{c}\text { Post-test } \\
\text { median }\end{array}$ & $P$ \\
\hline \multicolumn{4}{|l|}{ Dietary (scores) } \\
\hline Feeding habits $^{a}$ & 2.38 & 2.25 & $0.016^{*}$ \\
\hline Instrumental feeding & 2.00 & 1.90 & 0.100 \\
\hline Emotional feeding & 3.86 & 4.07 & $0.008^{* *}$ \\
\hline $\begin{array}{l}\text { Promoting and encouragement } \\
\text { to eat }\end{array}$ & 3.78 & 4.00 & 0.486 \\
\hline \multicolumn{4}{|l|}{ Control over eating } \\
\hline $\begin{array}{l}\text { Eating habits (four significant items } \\
\text { from } 45 \text { questions) })^{b}\end{array}$ & 3.00 & 2.00 & $0.007^{* *}$ \\
\hline Battle during mealtime & 3.00 & 3.00 & $0.049 *$ \\
\hline Picky eating behavior & 2.00 & 2.00 & $0.039 *$ \\
\hline Consumption of salty food. & 5.00 & 4.00 & $0.022^{*}$ \\
\hline Supervision for children & & & \\
\hline
\end{tabular}

\begin{tabular}{|c|c|c|c|}
\hline \multicolumn{4}{|c|}{ Physical activity time (minutes) } \\
\hline \multicolumn{4}{|c|}{ Vigorous } \\
\hline Mothers & $<10$ & $<10$ & $0.015^{*}$ \\
\hline Weekday & $<10$ & $<10$ & 0.109 \\
\hline Weekend & 45 & 130 & $0.036^{*}$ \\
\hline \multicolumn{4}{|c|}{ Domestic helpers } \\
\hline \multicolumn{4}{|l|}{ Moderate } \\
\hline \multicolumn{4}{|c|}{ Children (including vigorous) } \\
\hline Weekdays & 60 & 87.5 & 1.000 \\
\hline Weekend & 153.5 & 195 & 0.626 \\
\hline Mothers & $<10$ & $<10$ & 0.348 \\
\hline Weekday & $<10$ & $<10$ & 0.283 \\
\hline Weekend & 102.5 & 300 & $0.033^{*}$ \\
\hline \multicolumn{4}{|c|}{ Domestic helpers } \\
\hline \multicolumn{4}{|c|}{ Weekday } \\
\hline \multicolumn{4}{|l|}{ Light } \\
\hline \multicolumn{4}{|l|}{ Children } \\
\hline Weekdays & 95 & 90 & 0.864 \\
\hline Weekend & 145 & 152.5 & 0.607 \\
\hline Mothers & 120 & 125 & 0.607 \\
\hline Weekday & 60 & 60 & 0.584 \\
\hline Weekend & 292.5 & 315 & 0.607 \\
\hline \multicolumn{4}{|c|}{ Domestic helpers } \\
\hline Weekday & & & \\
\hline
\end{tabular}

Sedentary time (minutes)

Children

\begin{tabular}{|c|c|c|c|}
\hline Weekday & 90 & 60 & 0.884 \\
\hline Weekend & 120 & 137.5 & 0.486 \\
\hline Mothers & 292.5 & 180 & 0.082 \\
\hline Weekday & 130 & 90 & 0.063 \\
\hline Weekend & 236 & 256 & 0.617 \\
\hline \multicolumn{4}{|c|}{ Domestic helpers } \\
\hline Weekday & & & \\
\hline
\end{tabular}

sessions provide support for this goal being achieved: “...I want to highlight that as a family, we had a "stranger," a "helper." "She is now a part of the family, and through this program I feel our visions become uniform. Now she knows what we want, how she wanted to guide my daughter."

In general, most of the family-based interventions promoting healthy lifestyle behaviors target parents or grandparents. To our knowledge, none of them has taken into account the common practice in $\mathrm{HK}$, where domestic helpers are highly involved in the upbringing of children, creating a so called "extended family". Therefore, the foreign domestic workers who have caregiver roles in the families should be actively involved, together with the other significant caregivers, in the delivery of healthy lifestyle interventions for young children.

As we found in our study, the primary reason why the families did not sign up for the program or left the program before completion was time constraints. This is consistent with the findings of other obesity intervention program research that points to how the time crunch experienced by many families presents a major obstacle to their participation in needed health education/lifestyle modification type programs (38). To address this issue, the viability of offering the program in different formats may be considered, e.g., on weekends instead of weekdays, for an intensive 3-4 d program instead of spread out over 4 months, and perhaps even via online delivery.

One of the aims of this pilot program was to evaluate the "connectedness to nature" element, as it is crucial to understand whether nature based health-promoting interventions can be effective. Several relevant tools are available, but all of them target adults and older children, e.g., the "Children's connection to nature index" (38) and were not suitable for HK children of much younger age. We therefore further adapted the scale, creating a robust and valid instrument, suitable for studies associated to nature relatedness for preschool children in HK (under review).

To some extent, the lack of program impact on participating children playtime runs counter to findings from research indicating that programs with nature-related activities tend to increase physical activity (10-13). Hence, further possibilities were found for amplifying child's exposure to natural elements, such as conducting outdoor activities on open grassy areas (as recommended in a US Institute of Medicine report on prevention policies to address early childhood obesity) (16), including more activities that weave in plants and gardening as ways to teach about nutrition (15) and reducing reluctance to try new foods including fruits and vegetables (17). Additional ideas for expanding on the platform of "connectedness to nature" related activities come from the families themselves. Some parents mentioned an interest in participating in multifamily play groups engaged in nature-related activities; however, they felt the need of help in constructing and conducting such activities. Several caregivers illustrated how their children gained a better understanding of the connection between food and nature: "My son learned the food that we eat is coming from the ground and he appreciates the farmer and the land." "We used to ignore the growing process of foods, which 


\section{Articles | Sobkoetal.}

Table 5. Screening for factors which influenced the effectiveness on dietary habits

\begin{tabular}{|c|c|c|c|c|c|c|c|c|c|c|c|c|}
\hline & \multicolumn{2}{|c|}{ IF } & \multicolumn{2}{|c|}{ PE } & \multicolumn{2}{|c|}{$\begin{array}{l}\text { Battle during } \\
\text { mealtime }\end{array}$} & \multicolumn{2}{|c|}{$\begin{array}{l}\text { Picky eating } \\
\text { behaviors }\end{array}$} & \multicolumn{2}{|c|}{$\begin{array}{l}\text { Consumption of } \\
\text { salty food }\end{array}$} & \multicolumn{2}{|c|}{$\begin{array}{l}\text { Supervision of the } \\
\text { child }\end{array}$} \\
\hline & $r_{s} / x^{2}$ & $P$ & $r_{s} / x^{2}$ & $P$ & $r_{s} / x^{2}$ & $P$ & $r_{s} / x^{2}$ & $P$ & $r_{s} / x^{2}$ & $P$ & $r_{s} / x^{2}$ & $P$ \\
\hline \multicolumn{13}{|l|}{ Children } \\
\hline Gender & 2.236 & 0.135 & 0.852 & 0.356 & 1.000 & 0.317 & 0.009 & 0.923 & 0.556 & 0.456 & 0.107 & 0.744 \\
\hline z-BMI & 0.182 & 0.280 & -0.107 & 0.527 & 0.086 & 0.613 & -0.109 & 0.521 & -0.039 & 0.816 & 0.369 & $0.025^{*}$ \\
\hline Age (month) & -0.111 & 0.506 & 0.184 & 0.268 & 0.108 & 0.519 & 0.201 & 0.226 & -0.156 & 0.349 & -0.392 & $0.015^{*}$ \\
\hline Length of birth & 0.027 & 0.880 & -0.175 & 0.322 & -0.073 & 0.682 & 0.048 & 0.788 & -0.066 & 0.710 & -0.007 & 0.971 \\
\hline \multicolumn{13}{|l|}{ Mothers } \\
\hline Age & 0.023 & 0.893 & 0.135 & 0.427 & 0.168 & 0.319 & 0.194 & 0.251 & -0.087 & 0.610 & -0.327 & $0.048^{*}$ \\
\hline BMI & -0.080 & 0.639 & 0.362 & $0.028^{*}$ & 0.170 & 0.314 & 0.121 & 0.475 & 0.118 & 0.486 & -0.113 & 0.505 \\
\hline \multicolumn{13}{|l|}{ Family } \\
\hline Parents' education level ${ }^{a}$ & - & - & - & - & - & - & - & - & - & - & - & - \\
\hline Monthly income & 0.553 & 0.759 & 3.677 & 0.159 & 3.073 & 0.215 & 2.523 & 0.283 & 4.431 & 0.109 & 1.668 & 0.434 \\
\hline Only one child & 0.001 & 0.976 & 0.011 & 0.917 & 3.823 & 0.051 & 1.116 & 0.291 & 0.271 & 0.602 & 0.981 & 0.322 \\
\hline Family structure & 1.148 & 0.284 & 0.394 & 0.530 & 0.219 & 0.640 & 0.204 & 0.652 & 0.044 & 0.834 & 2.381 & 0.123 \\
\hline Numbers of computers & 6.312 & 0.177 & 1.094 & 0.895 & 2.190 & 0.701 & 1.195 & 0.879 & 2.780 & 0.595 & 1.949 & 0.745 \\
\hline Numbers of TVs & 3.297 & 0.192 & 2.575 & 0.276 & 3.547 & 0.170 & 5.946 & 0.051 & 3.207 & 0.201 & 0.360 & 0.835 \\
\hline \multicolumn{13}{|l|}{ Domestic helpers } \\
\hline Age & 0.034 & 0.840 & -0.249 & 0.131 & -0.296 & 0.071 & -0.116 & 0.487 & -0.294 & 0.073 & -0.053 & 0.751 \\
\hline Mothers & 0.404 & 0.525 & 2.108 & 0.147 & 0.461 & 0.497 & 0.138 & 0.710 & 4.215 & $0.040^{*}$ & 0.202 & 0.653 \\
\hline Helpers & 3.263 & 0.071 & 1.208 & 0.272 & 1.034 & 0.309 & 4.639 & 0.031 & 0.757 & 0.384 & 0.256 & 0.613 \\
\hline \multicolumn{13}{|l|}{ Child's meal } \\
\hline Mothers & 0.005 & 0.942 & 4.952 & $0.026^{*}$ & 0.034 & 0.854 & 0.820 & 0.365 & 0.229 & 0.632 & 0.026 & 0.873 \\
\hline Helpers & 0.621 & 0.431 & 2.525 & 0.112 & 0.034 & 0.854 & 3.878 & $0.049^{*}$ & 0.962 & 0.327 & 1.101 & 0.294 \\
\hline \multicolumn{13}{|l|}{ Child's recipes } \\
\hline Mothers & 0.280 & 0.597 & 2.861 & 0.091 & 0.942 & 0.332 & 0.069 & 0.793 & 2.905 & 0.088 & 0.018 & 0.894 \\
\hline Helpers & 0.345 & 0.557 & 0.089 & 0.765 & 0.043 & 0.835 & 4.393 & 0.036 & 0.002 & 0.968 & 0.049 & 0.824 \\
\hline \multicolumn{13}{|l|}{ Cooking method } \\
\hline Mothers & 0.023 & 0.880 & 3.280 & 0.070 & 1.855 & 0.173 & 1.683 & 0.195 & 0.145 & 0.703 & 0.218 & 0.641 \\
\hline Helpers & 0.050 & 0.824 & 0.020 & 0.887 & 1.154 & 0.283 & 1.073 & 0.300 & 0.285 & 0.593 & 0.492 & 0.483 \\
\hline \multicolumn{13}{|l|}{ Cooking } \\
\hline Mothers & 0.000 & 1.000 & 4.656 & $0.031^{*}$ & 0.049 & 0.825 & 1.178 & 0.278 & 2.986 & 0.084 & 0.001 & 0.978 \\
\hline Helpers & 1.997 & 0.158 & 0.918 & 0.338 & 0.000 & 0.984 & 7.342 & $0.007^{* *}$ & 4.075 & $0.044^{*}$ & 0.648 & 0.421 \\
\hline
\end{tabular}

IF, instrumental feeding; PE, promoting and encourage to eat; Battle during mealtime:"There is always a battle during mealtime."; Picky eating behaviors:"He/She is a picky eater."; Consumption of salty food:"I allow him/her to eat the salty foods"; Supervision of the child:"I (or caregiver) look after him/her, when he/she is eating."r, for continuous independent variables in Spearman's rank correlation test, while $x^{2}$ for category variables in Kruskal-Wallis $\mathrm{H}$ tests. a all of the parents' education level are university or above ${ }^{*} P<0.05 ;{ }^{* *} P<0.01$. 
indeed involved efforts from farmers, as well as nurtured by the nature. My kid has learnt that natural ingredients, water and soil are important in terms of "producing" foods, instead of buying food from market."

To gain a better insight into how families communicate, cooperate, and make plans and decisions with regard to eating habits, physical activity and ways of engaging nature, a more extensive and formal qualitative method would be necessary to complement the quantitative data. One strategy would be to conduct an extensive qualitative interview process, possibly utilizing a focus group format similar to the one developed to explore family communication dynamics related to eating habits (39).

\section{Drawbacks and Limitations}

Some limitations of this study should be noted, keeping in mind that this study was a useful resource to test and adjust the methods, instruments, and logistics. One of the limitations was that results from the small sample size may not be representative for the entire HK population. Furthermore, the pilot identified some drawbacks in measuring instruments (e.g., subjective measurements of physical activity and child's eating behaviors). Physical activity levels and times data was obtained from a subjective instrument (International Physical Activity Questionnaire and Physical Activity Questionnaire for Preschool-aged Children (Pre-PAQ)), and in the future randomized controlled trial (RCT) we will consider including a more objective measurement, such as pedometers or ActiGraphs. Although some improvements were found in children's eating behaviors (e.g., in less conflicts during mealtime and less "picky eating"), these results should be considered as tentative findings as the Hong Kong Children's Dietary Habit Questionnaire (HKCDHQ) instrument is still under validation. Thus, before starting the RCT, we will complete the validation first or choose another validated questionnaire (Children's Eating Behaviour questionnaire (40)). In addition, since the nature relatedness scale is currently being validated by our research team, we did not report those results in this pilot study.

The immediate effect after the program is encouraging, and a follow-up study to examine whether this intervention has a lasting effect when comparing to a control group of similar age without receiving a similar educational program is a natural next step. The following practices should be measured and added to the upcoming RCT: Parental self-efficacy for correct practices, Limit settings, Parental modeling of healthy habits, diet, active play and "connectedness to nature".

The long-term intention of "Play\&Grow" was to generate a final program with long-term sustainable health benefits to HK's current and future population. Over time, these benefits may be reflected in reduced prevalence of obesity amongst children and a concomitant reduction in healthcare costs in the public and private sectors. Furthermore, the results of the study could be of relevance to people living in other metropolitan areas or cities, which extends the impact of the study from local to global communities. In addition to these primary impacts, the study has an added scientific value by developing several important protocols and measurement instruments,
Table 6. Screening for family-related factors which influenced the effectiveness on physical active time

\begin{tabular}{|c|c|c|c|c|c|c|}
\hline & \multicolumn{2}{|c|}{$\begin{array}{l}\text { Parents vigorous } \\
\text { PA (weekday) }\end{array}$} & \multicolumn{2}{|c|}{$\begin{array}{c}\text { Domestic Helpers' } \\
\text { vigorous PA }\end{array}$} & \multicolumn{2}{|c|}{$\begin{array}{c}\text { Domestic Helpers } \\
\text { moderate PA }\end{array}$} \\
\hline & $r_{s} / x^{2}$ & $P$ & $r_{s} / x^{2}$ & $P$ & $r_{s} / x^{2}$ & $P$ \\
\hline \multicolumn{7}{|l|}{ Children } \\
\hline Gender & 0.512 & 0.474 & 1.014 & 0.314 & 0.018 & 0.895 \\
\hline z-BMI & 0.158 & 0.351 & -0.108 & 0.523 & -0.132 & 0.435 \\
\hline Age (month) & 0.131 & 0.433 & 0.205 & 0.217 & -0.130 & 0.435 \\
\hline Weight of birth & 0.137 & 0.413 & -0.067 & 0.689 & -0.151 & 0.526 \\
\hline Length of birth & 0.145 & 0.413 & 0.024 & 0.893 & -0.040 & 0.824 \\
\hline \multicolumn{7}{|l|}{ Mothers } \\
\hline Age & -0.103 & 0.545 & 0.217 & 0.197 & -0.033 & 0.848 \\
\hline BMI & 0.081 & 0.636 & 0.262 & 0.118 & -0.166 & 0.327 \\
\hline $\begin{array}{l}\text { Weeks of } \\
\text { pregnancy }\end{array}$ & 0.002 & 0.992 & -0.225 & 0.175 & -0.147 & 0.377 \\
\hline Work situation & 7.045 & 0.134 & 6.026 & 0.197 & 4.058 & 0.398 \\
\hline Delivery method & 0.001 & 0.970 & 0.786 & 0.375 & 0.145 & 0.703 \\
\hline
\end{tabular}

\begin{tabular}{|c|c|c|c|c|c|c|}
\hline \multicolumn{7}{|l|}{ Family } \\
\hline $\begin{array}{l}\text { Parents' } \\
\text { education level }\end{array}$ & - & - & - & - & - & - \\
\hline Monthly income & 0.771 & 0.680 & 0.235 & 0.889 & 2.388 & 0.303 \\
\hline Only one child & 0.099 & 0.753 & 0.316 & 0.574 & 0.138 & 0.710 \\
\hline Family structure & 0.355 & 0.551 & 0.749 & 0.387 & 0.023 & 0.879 \\
\hline $\begin{array}{l}\text { Numbers of } \\
\text { computers }\end{array}$ & 1.256 & 0.262 & 0.744 & 0.388 & 6.842 & $0.009^{* *}$ \\
\hline Numbers of TVs & 2.437 & 0.296 & 2.113 & 0.348 & 0.341 & 0.843 \\
\hline \multicolumn{7}{|c|}{ Domestic helpers } \\
\hline Age & -0.212 & 0.201 & 0.123 & 0.462 & 0.050 & 0.767 \\
\hline Education level & 1.480 & 0.687 & 2.320 & 0.509 & 1.584 & 0.663 \\
\hline BMI & -0.193 & 0.245 & -0.083 & 0.621 & 0.067 & 0.690 \\
\hline
\end{tabular}

\section{Responsibility}

Looking after the child

\begin{tabular}{lllllll} 
Mothers & 0.276 & 0.600 & 0.200 & 0.655 & 0.656 & 0.418 \\
$\begin{array}{l}\text { Helpers } \\
\text { Child's meal }\end{array}$ & 0.109 & 0.741 & 0.065 & 0.798 & 0.002 & 0.965 \\
$\begin{array}{l}\text { Mothers } \\
\text { Helpers }\end{array}$ & 1.068 & 0.302 & 6.172 & $0.013^{*}$ & 1.684 & 0.194 \\
$\begin{array}{l}\text { Child's recipes } \\
\text { Mothers }\end{array}$ & 0.266 & 0.606 & 3.333 & 0.068 & 0.482 & 0.487 \\
$\begin{array}{l}\text { Helpers } \\
\text { Cooking method }\end{array}$ & 0.002 & 0.967 & 0.316 & 0.574 & 1.443 & 0.230 \\
$\begin{array}{l}\text { Mothers } \\
\text { Helpers }\end{array}$ & 0.186 & 0.667 & 0.848 & 0.357 & 1.305 & 0.253 \\
Cooking & 0.087 & 0.768 & 0.000 & 0.987 & 1.260 & 0.262 \\
Mothers & 0.008 & 0.927 & 3.819 & 0.051 & 0.442 & 0.506 \\
$\begin{array}{l}\text { Helpers } \\
\text { Moln }\end{array}$ & 0.328 & 0.567 & 0.426 & 0.514 & 0.215 & 0.643 \\
\hline
\end{tabular}

$r_{s}$ for continuous independent variables in Spearman's rank correlation test, while $x^{2}$ for category variables in Kruskal-Wallis tests. ${ }^{\text {a All }}$ of the parents' education level are university or above ${ }^{*} P<0.05 ;{ }^{* *} P<0.01$. 
Table 7. Summary of the simultaneous multiple regression analysis of univariate predictors for the influences on dietary outcomes

\begin{tabular}{|c|c|c|c|c|c|c|}
\hline \multicolumn{2}{|c|}{ Outcomes/predictors } & $B$ & $S E_{B}$ & B & $t$ & $p(t)$ \\
\hline \multicolumn{7}{|c|}{ Promoting and encouragement to eat } \\
\hline \multirow[t]{4}{*}{ Model 1} & Mothers'BMI & 0.008 & 0.004 & 0.348 & 2.083 & $0.045^{*}$ \\
\hline & Child's birth weight & $<0.000$ & 0.000 & -0.386 & -2.252 & $0.031^{*}$ \\
\hline & Mothers'responsibility for meal & -0.035 & 0.037 & -0.153 & -0.946 & 0.351 \\
\hline & & \multicolumn{5}{|c|}{$r=0.493, r^{2}=0.243$, adjusted $r^{2}=0.175 . F(3,33)=3.54, P=\mathbf{0 . 0 2 5} *$} \\
\hline \multirow[t]{4}{*}{ Model 2} & Mothers'BMI & 0.008 & 0.005 & 0.307 & 1.587 & 0.102 \\
\hline & Child's birth weight & $<0.000$ & 0.000 & -0.433 & -2.293 & 0.029 \\
\hline & Mothers' responsibility for meal & 0.001 & 0.052 & 0.006 & 0.025 & 0.981 \\
\hline & Mothers' responsibility for cooking & -0.068 & 0.064 & -0.229 & -1.068 & 0.294 \\
\hline
\end{tabular}

$r=0.500, r^{2}=0.250$, adjusted $r^{2}=0.153 . F(4,31)=2.582, P=0.057$

\begin{tabular}{|c|c|c|c|c|c|c|}
\hline \multicolumn{7}{|c|}{ Picky eating behavior } \\
\hline \multirow[t]{2}{*}{ Model 1} & Effectiveness on instrumental feeding practice & 0.141 & 0.130 & 0.168 & 1.087 & 0.285 \\
\hline & Helpers' responsibility for cooking & -0.305 & 0.117 & -0.400 & -2.596 & $0.014^{*}$ \\
\hline \multirow[t]{2}{*}{ Model 2} & Effectiveness on instrumental feeding practice & 0.138 & 0.132 & 0.164 & 1.049 & 0.302 \\
\hline & Helpers' responsibility for meal & -0.064 & 0.129 & -0.098 & -0.496 & 0.623 \\
\hline \multicolumn{7}{|c|}{ Consumptions of salty food } \\
\hline & Mothers'responsibility for child & -0.417 & 0.155 & -0.398 & -2.684 & $0.011 *$ \\
\hline & Helpers'responsibility for meal & -0.361 & 0.165 & -0.324 & -2.184 & $0.036^{*}$ \\
\hline & & \multicolumn{5}{|c|}{$r=0.502, r^{2}=0.252$, adjusted $r^{2}=0.208 . F(2,34)=5.737, P=\mathbf{0 . 0 0 7}^{* *}$} \\
\hline
\end{tabular}

${ }^{*} P<0.05 ;{ }^{* *} P<0.01 . B$ : unstandardized regression coefficient $S E_{B}$ : Standard error of the coefficient $B$ : standardized coefficient.

especially the Nature Relatedness Scale for preschool children (subsequent work).

\section{Conclusion}

To the best of our knowledge, this is the first study of its kind in $\mathrm{HK}$, promoting healthy lifestyle early in life and targeting not only the parents but the domestic helpers as well. The results therefore are expected to add value to the existing recommendations on physical activity and diet in children and, by introducing an environmental factor, "connectedness to nature", to the healthy lifestyle recommendations. The impact of some of the actions taken during this pilot project are recognized, acknowledged, and highly appreciated by the caregivers and especially the foreign domestic workers in participating families.

In conclusion, by conducting the "Play\&Grow" pilot study, we have successfully evaluated study design, protocols, methodology, and logistics. The strategies were adopted and modified and are now deemed suitable for a larger-scale RCT to promote healthy lifestyles for young children and their families.

\section{ACKNOWLEDGMENTS}

The authors would like to thank the Play\&Grow staff members, and the families who participated in the program. We furthermore thank Emily Wong for invaluable assistance in delivering this program.

\section{AUTHOR CONTRIBUTIONS}

T.S. is the principal investigator of the study, she initiated and laid the main design of the study. All the authors participated in further development of the design, tools and wrote the manuscript. All the authors read and approved the final manuscript.

\section{STATEMENT OF FINANCIAL SUPPORT}

The study is supported by HKU SEED funding, GHELCH and Knowledge Exchange Grant.

Disclosure: The authors declare no competing interests.

\section{REFERENCES}

1. World Health Organization. Global Strategy on Diet, Physical Activity and Health, 2004. http://www.who.int/dietphysicalactivity/en/.

2. Palmer S. Toxic childhood: how the modern world is damaging the our children and what we can do about it. London, England: Orion, 2006.

3. Louv R. Last child in the woods: saving our children from nature-deficit disorder. Chapel Hill, N.C.: Algonquin Books of Chapel Hill, 2008.

4. Chan CM, Deave T, Greenhalgh T. Obesity in Hong Kong Chinese preschool children: where are all the nurses? J Pediatr Nurs 2010;25: 264-73.

5. Lo K, Cheung C, Lee A, Tam WW, Keung V. Associations between parental feeding styles and childhood eating habits: a survey of Hong Kong preschool children. PLoS One 2015;10:e0124753.

6. Leung S, Leung C, Luk W-Y. A Survey of Infant and Young Child Feeding in Hong Kong: Parental Perceptions and Practices. Family Health Service, The Department of Health Hong Kong SAR Government 2012.

7. Tam VC. Foreign domestic helpers in Hong Kong and their role in childcare provision. In: Momsen $\mathrm{JH}$, ed. Gender, Migration and Domestic Service. New York: Routledge, 2003:263-76.

8. Tam VC. A family ecological analysis of child care use in Hong Kong. Child Soc 2001;15:181-92.

9. Veselinovska SS, Osogovska TL. Engagement of students in environmental activities in school. Procedia Soc Behav Sci 2012;46:5015-20. 
10. Cleland V, Crawford D, Baur LA, Hume C, Timperio A, Salmon J. A prospective examination of children's time spent outdoors, objectively measured physical activity and overweight. Int J Obes (Lond) 2008;32:1685-93.

11. Thompson Coon J, Boddy K, Stein K, Whear R, Barton J, Depledge MH. Does participating in physical activity in outdoor natural environments have a greater effect on physical and mental wellbeing than physical activity indoors? A systematic review. Environ Sci Technol 2011;45:1761-72.

12. Dyment JE, Bell AC. Grounds for movement: green school grounds as sites for promoting physical activity. Health Educ Res 2008;23:952-62.

13. Bell JF, Wilson JS, Liu GC. Neighborhood greenness and 2-year changes in body mass index of children and youth. Am J Prev Med 2008;35:547-53.

14. Monasta L, Batty GD, Macaluso A, et al. Interventions for the prevention of overweight and obesity in preschool children: a systematic review of randomized controlled trials. Obes Rev 2011;12:e107-18.

15. Hedberg A, Lewis T, Sharma S. PLANT gardens: preschoolers learn about nutrition through gardens curriculum development and pre-testing. J Am Diet Assoc 2009;109:A47.

16. Birch LL, Parker L, Burns A. Early childhood obesity prevention policies. Washington, DC: National Academies Press; 2011.

17. Institute for Agriculture and Trade Policy. Farm to Child Care, 2012. http:// www.iatp.org/issue/farm-to-childcare.

18. Timmons BW, Proudfoot NA, MacDonald MJ, Bray SR, Cairney J. The health outcomes and physical activity in preschoolers (HOPP) study: rationale and design. BMC Public Health 2012;12:284.

19. Campbell K, Hesketh K, Crawford D, Salmon J, Ball K, McCallum Z. The Infant Feeding Activity and Nutrition Trial (INFANT) an early intervention to prevent childhood obesity: cluster-randomised controlled trial. BMC Public Health 2008;8:103.

20. Patterson GR. Performance models for parenting: a social interactional perspective. In: Grusec JE, Kuczynski LE, eds. Parenting and Children's Internalization of Values: A Handbook of Contemporary Theory. New Jersey: John Wiley \& Sons Inc, 1997:193-226.

21. Nelson CS, Wissow LS, Cheng TL. Effectiveness of anticipatory guidance: recent developments. Curr Opin Pediatr 2003;15:630-5.

22. Mullis F. Active parenting: an evaluation of two Adlerian parent education programs. J Individ Psychol 1999;55:225-32.

23. Sobko T, Tse M, Kaplan M. A randomized controlled trial for families with preschool children - promoting healthy eating and active playtime by connecting to nature. BMC Public Health 2016;16:505.

24. Lohman TG, Roche AF, Martorell R. Anthropometric Standardization Reference Manual. Champaign, IL: Human Kinetics Books, 1988.

25. Reilly JJ, Coyle J, Kelly L, Burke G, Grant S, Paton JY. An objective method for measurement of sedentary behavior in 3- to 4-year olds. Obes Res 2003;11:1155-8.

26. World Health Organization. WHO Child Growth Standards: Length/ height-for-age, weight-for-age, weight-for-length, weight-for-height and body mass index-for-age: Methods and development, 2006. http://www. who.int/childgrowth/standards/technical_report/en/.

27. World Health Organization. Growth velocity based on weight, length and head circumference. WHO Child Growth Standards: Methods and development, 2009. http://www.who.int/childgrowth/publications/technical_report_velocity/en/.

28. Skouteris H, McCabe M, Swinburn B, Hill B. Healthy eating and obesity prevention for preschoolers: a randomised controlled trial. BMC Public Health 2010;10:220.

29. Tam W, Keung V, Lee A, Lo K, Cheung C. Chinese translation and validation of a parental feeding style questionnaire for parents of Hong Kong preschoolers. BMC Public Health 2014;14:1194.

30. Chan R, Woo J, Sea M, et al. Eat for Fun (識食家 “FUN") - a parenting workshop to enhance parental skills on handling children's mealtime behaviours and making healthy food choices for young children in Hong Kong. The Research Fund Secretariat, The Food and Health Bureau, HKSAR, 2015.

31. Booth M. Assessment of physical activity: an international perspective. Res Q Exerc Sport 2000;71 Suppl 2:114-20.

32. Dwyer GM, Hardy LL, Peat JK, Baur LA. The validity and reliability of a home environment preschool-age physical activity questionnaire (PrePAQ). Int J Behav Nutr Phys Act 2011;8:86.

33. Anderson DR, Field DE, Collins PA, Lorch EP, Nathan JG. Estimates of young children's time with television: a methodological comparison of parent reports with time-lapse video home observation. Child Dev 1985;56: 1345-57.

34. Colquitt JL, Loveman E, O'Malley C, et al. Diet, physical activity, and behavioural interventions for the treatment of overweight or obesity in preschool children up to the age of 6 years. Cochrane Database Syst Rev 2016;3:CD012105.

35. Vereecken C, Haerens L, De Bourdeaudhuij I, Maes L. The relationship between children's home food environment and dietary patterns in childhood and adolescence. Public Health Nutr 2010;13(10A):1729-35.

36. Timmons BW, Proudfoot NA, MacDonald MJ, Bray SR, Cairney J. The health outcomes and physical activity in preschoolers (HOPP) study: rationale and design. BMC Public Health 2012;12:284.

37. Fulkerson JA, Friend S, Flattum C, et al. Promoting healthful family meals to prevent obesity: HOME Plus, a randomized controlled trial. Int J Behav Nutr Phys Act 2015;12:154.

38. Cheng JC-H, Monroe MC. Connection to nature children's affective attitude toward nature. Environ Behav 2012;44:31-49.

39. Kaplan M, Kiernan NE, James L. Intergenerational family conversations and decision making about eating healthfully. J Nutr Educ Behav 2006;38:298-306.

40. Wardle J, Guthrie CA, Sanderson S, Rapoport L. Development of the Children's Eating Behaviour Questionnaire. J Child Psychol Psychiatry 2001;42:963-70. 